\title{
The Construction of Application Oriented Personnel Training System in the Transformation and Development
}

\author{
Jiang Yuhua ${ }^{1, a}$, Qian Shuang ${ }^{2, a}$ \\ ${ }^{1}$ Baicheng Normal College, Media Institute, Baicheng, Jilin \\ ${ }^{2}$ Thirty - First Middle School, Jiutai District, Changchun City, Jilin Province \\ awliao9590@163.com
}

\section{Keywords: Transformation and Development; Applied Talents; Practical Teaching}

\begin{abstract}
As an undergraduate college, how to achieve the service of local economic and social development, production and education integration of school and enterprise cooperation, training and application of skilled personnel, and enhance the ability of students to start employment is the key to determine the survival and development of the school. And such a school because of the development of the history of relatively short, in practice teaching there are still out of touch between theory and practice, the lack of practical resources, school-enterprise cooperation is not smooth, the concept of practice is not fully established, teachers practice is not strong, Not to practice the purpose of teaching many questions. So it is necessary to construct a practical teaching system. The application of applied talents is one of the main contents of the transformation and development of colleges and universities. Practical teaching is an important link to realize the goal of applying talents. This paper explores and expounds the problems existing in the practice teaching of the new undergraduate colleges from the aspects of the practice education idea, the practice syllabus, the guarantee system of the practice teaching and the evaluation system of the practical teaching, and forms the goal of cultivating the target the complete practice of teaching system.
\end{abstract}

\section{Introduction}

The talents training goal of course is to realize the basic elements, is a basic guarantee to realize the objective of school education; Course construction is the basis of the specialty construction and key, is the main way to improve teaching quality. We will deepen reform of the curriculum system and teaching content updates, improve the quality of teaching and curriculum construction level is the key of personnel training. Applied guided by social needs of personnel training, cultivate a solid theory foundation, wide professional knowledge, strong practical ability, high comprehensive quality, high-quality practical engineering technical talents with innovative consciousness. As a engineering talent raise the basic elements of curriculum and teaching are the key points in the school to implement the standards after refining, defined in relation to the cultivation standard of knowledge, ability and quality can truly implemented, is whether it can develop the key to meet the needs of the engineering talents cultivation standard. How to construct the curriculum system, developed to adapt to the economic and social development needs of high-quality practical talents with practical ability and innovative consciousness, and become the focus of the innovative applied talents training mode.

Domestic scholars believe that higher education has made remarkable progress over the years. Multilevel type development, the concept of scientific education and humanistic education and has gradually thorough popular feeling, but from the social development, demand for high quality talents in colleges and universities in personnel training mode, educational philosophy, many aspects, such as in the cultivation of university spirit still exists a lot of worthy of reflection, research and improvement. Especially on the issues of cultivating applied talents, how to against its talent spec targeted to carry out the cultural quality education also need to study and explore. Domestic scholars believe that the popularization of higher education into the stage of development, cultural quality education failure to appreciate the importance and urgency of cultural quality education work in the basic status of the talent cultivation in colleges and universities have not 
really reflect. The current college cultural quality education worker work for applied undergraduate talents cultivation to carry out the cultural quality education theory to inadequate preparation. Need for applied undergraduate talents training and culture quality education series research of the problem.

\section{Parsing and Its Scientific Definition of Applied Undergraduate Education Connotation}

Applied undergraduate education is an important system of higher education, is a traditional and scientific education system corresponding to the application of education system. Analysis from the perspective of philosophy and sociology, the relationship between human and the outside world is nothing more than to know the world and transform the world. To know the world mainly science activities, change is the world's leading engineering activities. In the process of know the world and transform the world, must by certain means, methods and tools, namely technical activities. About the relation of science, engineering, technology of philosophers have made various regulations, but, no matter how big difference between the rules of one thing is for sure, that's a technology is different from scientific system. The role of science is to understand, discovery and innovation as the core, the role of engineering is to practice, and application to construction as the core, both is mutually independent and contact each other and influence each other. We must not confuse them. Therefore, in the process of know the world and transform the world, scientific activities form the scientific system, corresponding to the science and education, scientific system made up of propositions and concepts, scientific education with the concept of basic knowledge and disciplines; Engineering technical activities form engineering technical system, the engineering technology system consists of activities and practice, corresponding to the engineering education, the education content in the project or the production process as the main line. They respectively to develop science-based, engineering and technology talents. Thus, applied education differs from pay attention to the scientific education theory system, is to emphasize application engineering education system.

Applied undergraduate education is along with the scientific and technological knowledge have evolved in response to a role in the development of society and promote the product. With the development of the first industrial revolution, science and technology in the field of social and economic production of the role is becoming more and more significant. But due to the time of the science and technology in the application of social and economic development is still in its infancy, determines the applied talents is the mid-level technical workers in the process of production, and the corresponding produced mainly elementary and intermediate technical personnel training of practical education. The wide application of high and new technology and change of the structure of social production, technical professional level and the higher the level, promotes the improvement and level of applied talents training, facilitate the movement of the applied education level high, applied education of undergraduate level. As a type of professional and technical personnel, senior professional and technical personnel is the main body and core of applied talents, the corresponding to applied senior specialized talents cultivation of undergraduate level as the main body of the applied undergraduate education has become the subject of applied education and the center link.

Specialized technical personnel is given priority to with application in the field of professional for the purpose of a liberal education. Applied undergraduate education is a kind of general education and professional it focus on the student system, solid basic theoretical knowledge learning and reserves, which the shape of scientists quality, future long-term development for the students lay a solid foundation, but also a kind of based on ability education, is for students to enter the reality and the future market employment or preparation for entrepreneurship education, namely the cultivation of the ability to engineer and training; therefore, the cultivation of applied undergraduate talents specifications, outstanding performance in practical ability and basic knowledge, strong learning ability, ability to adapt quickly, high innovation consciousness and comprehensive quality good high-level based on practicability, skilled, professional know-how of a liberal education.

Applied undergraduate education with the aim to cultivate application engineers and 
professional engineers, is the science of degree education and vocational element to form a unity and organic combination. Applied undergraduate education is given priority to with specialized knowledge from all walks of life, its training target is used for the purpose of production, construction, management, service and so on, in order to solve field problem is given priority to a line of professional engineers, the high and new science and technology into realistic productivity application engineer. Thus, applied undergraduate education is a kind of application for the science and the modern technology to provide academic and employment of students education in career preparation. It not only emphasizes to study the basic theories of science and technology, more emphasis on professional and industry relevant skills for future training. Therefore, the applied undergraduate education is a kind of academic education and vocational element to form a unity and organic combination of science.

Applied undergraduate education should be with high and new technology research and development and achievements as a main direction and main features. Applied undergraduate education is to transform the world as own duty, in the pursuit of academic capitalism, emphasizes the initiative to meet the needs of the reality of the economic and social development, social development needs of new and high technology research and development and the achievements as the key point, take the initiative to the basic research and teaching together with the industry innovation, focuses on the scientific understanding and scientific laws into realistic productivity.in this process, the day beneficial to the entrepreneurial university.

On the applied undergraduate education from the organization form and culture should be paid close attention to and social integration. Applied undergraduate education is to adapt to and meet the demand of take a new road to industrialization in China directly to production, construction, management, service and so on the first line of technology education practice needs, establish a social development needs as the goal of education thought. Applied undergraduate education and the integration of the society, must first clear the cultivation of students' social goal directed. Next, it is must emphasize applied talents must be useful to adapt to the social development. Useful, namely the applied undergraduate education professional knowledge and ability has the characteristics of systematic, timely and flexibility, can solve social and industry development current and future needs, can play a role in students into professional field, namely the usefulness of education content, in order to make the applied talents knowledge, skills, and continuing development of social requirement, the real development of applied undergraduate education and will meet the needs of society

\section{The Construction Goal of Applied Undergraduate Education}

Construction can meet the demand of applied talents of cultural quality education system. To construct a high level, applied undergraduate talents as the goal, through the university four years of undergraduate course education process of applied undergraduate talents culture quality education system, and establish a set of operation mechanism, to safeguard the quality of its making culture quality education can meet the need of applied talents grow up more.

The implementation of brand strategy, in the trial practice of the system in the process of brand demonstration role into full play. Through materials, pilot group verify that the system is scientific, and put forward the promotion plan, make it play a demonstration role in the higher education park.

The construction of open system of cultural quality education, research and education for cultural quality education in colleges and universities, the teaching activities of the win-win.

\section{The Construction of Applied Undergraduate Education Personnel Training System}

Dominated by the application of concept of talent education and training objectives. Applied undergraduate education is a kind of humanism education idea, is focused on preparing for future human career education. Is pragmatism education idea in the reality to carry forward and development. So the training goal is not the traditional discipline and academic standard, on the contrary is real docking, in order to meet the social demand as the guide, is the combination of 
theory and practice, production and labor, the combination of school and enterprise with the combination of education, it is more emphasis on students' autonomous learning ability and adaptability, emphasize up to some kind of professional post skills, emphasize to solve specific technical problems in practical production, and technical innovation and technical secondary development employment competition ability, adapt to the society with higher comprehensive qualities of a variety of position, namely life and survival ability, training is the modern technology, users, perpetrators and implements.

Build professional vocational elements as intermediary and course setting. Applied senior professional talents cultivation based on market demand and business needs as the guidance of professional education, in order to meet the diverse requirements of the talent and enterprise of the practical need of applied talents training and the cultivation of applied talents must stress according to the industry, industry and enterprise the required technical knowledge, skills, according to the principle of combining theory and practice of discipline knowledge restructuring, the applicability and strong emphasis on industry course activity module combination of pertinence. To follow the rules of discipline and knowledge inner link, on the basis of stress from set out actually, according to industry and business career and changing jobs demand installation flexibility and build curriculum. When setting and curriculum system, therefore, stressed by a representative of the enterprise on behalf of, subjects, professional experts, representatives of teachers and student representatives, composed of professional and curriculum committee, fully investigating and analyzing the changing of market, society to the talents training goal of school requirements, specifications, model, combined with the professional demand and the element of modern enterprise talent discipline specific academic requirements of the flexibility to formulate and modify major setting and course system plan.

The integration between production as the main characteristics of the training process. Applied senior specialized talents cultivation process fusion between production as the main characteristics and the way, in the education plan of applied talents and enterprises employing mechanism to realize the accommodation, the applied talents training mode and enterprise university plans to achieve seamless docking.

Ability to dominate the diversified evaluation system and evaluation methods of the cultivation of the applied senior specialized talents, implement is a kind of ability oriented education, the talent assessment and evaluation has also changed the traditional with only a piece of paper is to evaluate the quality of the students practice, practice the knowledge, skill and ability of comprehensive appraisal, set up is given priority to with application ability appraisal of quality examination and evaluation system, its characteristic is fully appreciated enterprise technical personnel to participate in, attach importance to students' practical ability, is a kind of open, flexible, individual quality assessment and evaluation.

\section{Conclusion}

The construction of institutions of higher learning should be closely around the applied undergraduate talents training target, applied undergraduate talents cultivation system research and the cultural quality education in many important problems, explore how to construct the talents training goal of based on the type of cultural quality education system and how to establish the quality guarantee mechanism to ensure the system running, this to clear the connotation of cultural quality of the applied undergraduate talents, deepening the theory of cultural quality education, promote the applied talents cultivation process optimization has a larger role in promoting, therefore, the subject has not only deepen the reform of the cultural quality education of theoretical value and practical guiding the practical value of the cultural quality of applied talents training.

\section{References}

[1] Wu Weining. Foreign Language Teaching in the Cultivation of Students' Foreign Language Quality [J]. Shaanxi Education, 2008 (10); 
[2] Ye Shujiang. On the Training Mode of Applied Talents in "Excellence Program" Project[J]. Research on Higher Education in Heilongjiang Province,2011(04);

[3] Liu Daoyu. On the Reform of Undergraduate Curriculum System[J]. Higher Education Exploration,2009(01);

[4] Lin Jian. Excellence Engineers Education Training Plans to Study Professional Training Scheme [J]. Higher Engineering Education Research , 2011(04);

[5] Zhai Bo. Education for The Major Innovation-Education Idea [J]. Education Research,2011(01).

[6] Sun Zeping. About the Reform of Applied Undergraduate Colleges and Universities Personnel Training[J]. The Study of Higher Education in China,2011(04). 